Volume 1, Nomor 2, Oktober 2020, 96-106

JTTM: Jurnal Terapan Teknik Mesin

p ISSN 2721-5377| e ISSN 2721-7825

\title{
REMAINING LIFE ASSESSMENT DAN KASUS LAJU KOROSI PADA LPG STORAGE TANK KAPASITAS 50 TON
}

\section{REMAINING LIFE ASSESSMENT AND CORROSION CASE ON LPG STORAGE TANK 50 TON CAPACITY}

\author{
Amam Fachrur Rozie ${ }^{1^{*}}$ \\ ${ }^{1 *}$ Institut Sains dan Teknologi Nasional, Jl. Moh. Kahfi II, Srengseng Sawah, Jagakarsa - Jakarta, Indonesia \\ * Koresponden Email: amamfachrur@gmail.com
}

\begin{abstract}
Abstrak. LPG Storage Tank berkapasitas 50 Ton yang telah terinstalasi dan beroperasi sejak tahun 2010 akan dikaji kelayakan dan sisa umur pakai dari pressure vessel tersebut. Metode pengujian yang dipergunakan adalah Non-Destructive Testing (NDT) - Ultrasonic Testing (UT) pada bagian shell dan head untuk mendapatkan nilai actual thickness dari pressure vessel serta dilakukan Visual Examination. Nilai thickness tersebut dipergunakan untuk menganalisis dan mengkalkulasi thickness required (Treq), nilai Corrosion Rate (CR), Maximum Allowable Working Pressure (MAWP) serta umur sisa (Remaining Life) dari $L P G$ Storage Tank tersebut. Dari hasil analisa serta perhitungan maka didapat umur sisa pakai dari $L P G$ Storage Tank kapasitas 50 Ton adalah 18 tahun dengan nilai laju korosi sebesar 0,043 mm/thn.
\end{abstract}

Kata Kunci: LPG Storage Tank 50 T, NDT-UT, CR, MAWP, Umur Sisa

Abstract. The LPG Storage Tank with a capacity of 50 tons, which has been installed and operating since 2010, will be assessed for its feasibility and the remaining useful life of the pressure vessel. The testing method used is Non-Destructive Testing (NDT) - Ultrasonic Testing (UT) on the shell and head to get the actual thickness value of the pressure vessel and Visual Examination is performed. The thickness value is used to analyze and calculate the thickness required (Treq), Corrosion Rate (CR) value, Maximum Allowable Working Pressure (MAWP) and the remaining life (Remaining Life) of the $L P G$ Storage Tank. From the results of the analysis and calculations, the remaining life of the LPG Storage Tank with a capacity of 50 tons is 18 years with a corrosion rate of $0.043 \mathrm{~mm} /$ year.

Keywords: LPG Storage Tank 50 T, NDT-UT, CR, MAWP, Remaining Life

\section{PENDAHULUAN}

Keselamatan merupakan aspek paling penting yang tidak boleh diabaikan. Karena hal tersebut berkaitan dengan keselamatan aset, keselamatan lingkungan dan keselamatan sumber daya manusia [1]. Maka dari itu perlu dilakukan proses pengkajian terhadap unit peralatan untuk mengetahui batasanbatasan keselamatan serta kelayakan dari suatu peralatan yang beroperasi. LPG Storage Tank merupakan bagian dari ranah bejana tekan atau pressure vessel yang berfungsi sebagai penampungan sementara LPG yang nantinya akan di distribusikan ke dalam tabung LPG $3 \mathrm{~kg}$ atau $12 \mathrm{Kg}$. Suatu $L P G$ storage tank dalam Stasiun Pengisian Bulk Elpiji (SPBE) yang telah beroperasi sejak tahun 2010 akan dilakukan proses rekalkulasi agar mengetahui laju korosi serta sisa umur pakai nya [2], hasil dan 
penelitian ini akan memberikan konklusi layak atau tidaknya sebuah $L P G$ Storage Tank yang telah beroperasi lebih dari 10 tahun ini. Metode ini menggunakan dua pendekatan yaitu metode NonDestructive Test (NDT) [3] dan Visual Inspection [4]. Pada gambar 1 merupakan gambar LPG Storage Tank 50 T. Tujuan dari penelitian ini untuk mengetahui kelayakan dan umur sisa [5] pada LPG Storage Tank $50 \mathrm{~T}$.

\subsection{Studi Literatur}

ASME VIII Div. 1 [6] [7] merupakan rujukan dasar dalam proses kalkulasi, karena LPG Storage Tank merupakan bagian dari bejana tekan. Thickness required (Treq) merupakan ketebalan minimum yang dipersyaratkan agar dapat bejana tekan beroperasi sesuai dengan desain awal, untuk memperhitungkan tebal yang disyaratkan [8].

treq $=\frac{P(R i+C a)}{S E-0,6 P}$

\section{Dimana :}

$\begin{array}{ll}\text { treq } & \text { : Ketebalan minimum }(\mathrm{mm})-\text { Shell } \\ \mathrm{P} & : \text { Tekanan desain }\left(\mathrm{kg} / \mathrm{cm}^{2}\right) \\ \mathrm{Ri} & : \text { Diameter dalam }(\mathrm{mm}) \\ \mathrm{Ca} & \text { : Corrosion allowances }(\mathrm{mm}) \\ \mathrm{S} & : \text { Allowable stress }\left(\mathrm{kg} / \mathrm{cm}^{2}\right) \\ \mathrm{E} & : \text { Joint Efficiency }\end{array}$

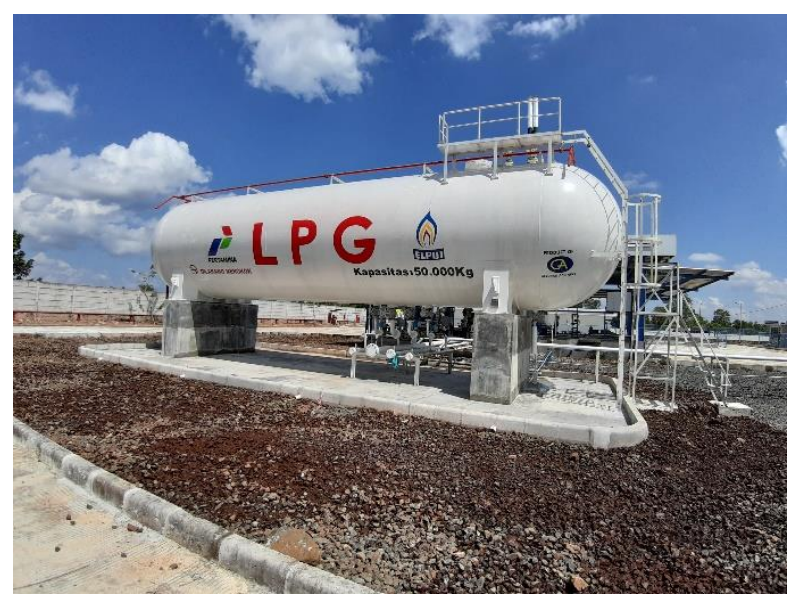

Gambar 1. LPG storage tank $50 \mathrm{~T}$

Sedangkan untuk menghitung tebal minimum pada head harus dilakukan proses identifikasi jenis head yang dipergunakan pada setiap bejana tekan, karena hal ini akan berpengaruh pada formula kalkulasi yang akan dipergunakan [9]. Setelah dilakukan identifikasi pada LPG Storage Tank maka didapat bahwa jenis head yang dipakai adalah tipe hemispherical head. Sehingga dipergunakan formula yang dijelaskan point 2 . 
treq $=\frac{P L}{2 S E-0,2 P}$

Dimana :

treq : Ketebalan minimum $(\mathrm{mm})-$ head

$\mathrm{L} \quad$ : Inside crown radius $(\mathrm{mm})$

$\mathrm{S} \quad$ : Allowable stress $(\mathrm{mm})-$ head

Selain memperhitungkan ketebalan minimum, penelitian ini juga memperhitungkan tingkat laju korosi [10]. Nilai laju korosi (corrosion rate) yang didapat nanti akan dipergunakan untuk menghitung tekanan maksimum yang diijinkan (MAWP). Formula yang dipergunakan.

\section{- Short term}

$C R: \frac{\text { t.prev-t.act }}{\text { years between t.prev and t.act }}$

- Long term

$C R: \frac{\text { t.nom-t.act }}{\text { years between t.nom and t.act }}$

Dimana :

CR : Laju korosi / corrosion rate $(\mathrm{mm} / \mathrm{thn})$

t.prev : Ketebalan sebelumnya (mm)

t.act : Ketebalan aktual (mm)

t.nom : Ketebalan nominal (mm)

Setelah mendapatkan nilai laju korosi selanjutnya adalah memperhitungkan tekanan maksimum yang diijinkan beroperasi (MAWP) dari LPG Storage Tank. Kondisi tersebut dapat mempergunakan formula.

MAWP Shell :

$M A W P=\frac{S E(\text { t.act }-2 C R . T)}{(R i+C A)+0,6(t . a c t-2 . C R . T)}$

MAWP Head (Hemispherical type)

$M A W P=\frac{S E(\text { t.act }-2 C R . T)}{L+0,2(\text { t.act-2.CR.T })}$

Dimana :

t.used : ketebalan minimum yang dipakai (mm)

$\mathrm{T} \quad$ : interval waktu inspeksi (tahun)

$\mathrm{L} \quad$ : inside crown radius $(\mathrm{mm})$

Setelah mendapatkan semua parameter perhitungan diatas, selanjutnya kita bisa menghitung sisa umur pakai dari $L P G$ Storage Tank $50 T$ tersebut dengan formula nomor 7. 
Remaining Life $=\frac{\text { t.actual-t.required }}{C R}$

Untuk menghitung sisa umur pakai antara head dan shell formula yang dipergunakan sama, hanya saja kedua hasil perhitungan akan dikomparasikan dan dicari nilai terendah sebagai hasil akhir dari sisa umur pakai. Dan dipakai sebagai sisa umur pakai dari LPG Storage Tank 50 T tersebut.

\section{METODE}

Tahapan-tahapan penelitian digambarkan melalui diagram alir penelitian pada gambar 2 .

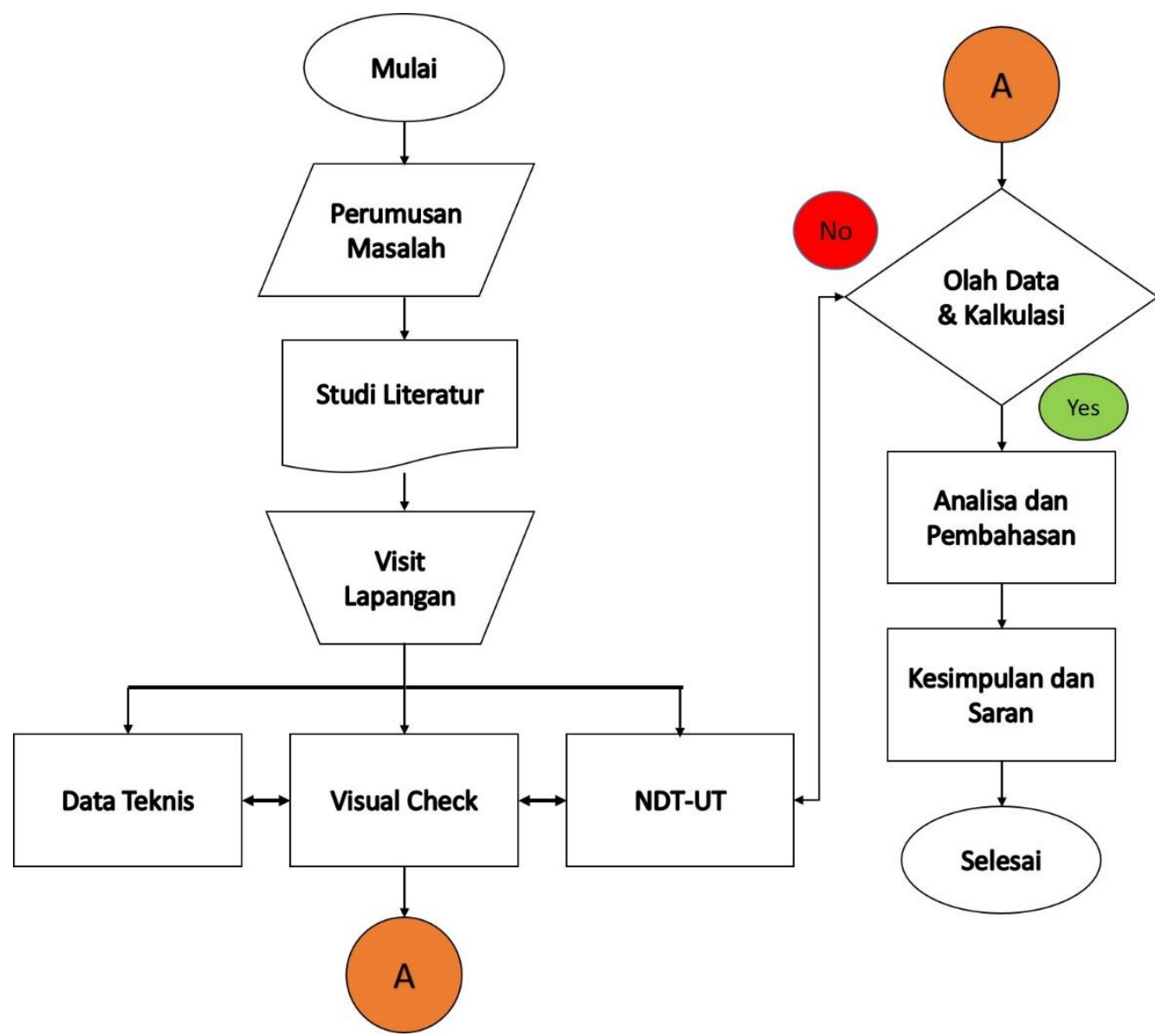

Gambar 2. Diagram alir penelitian

Lokasi pengujian dilakukan di salah satu Stasiun Pengisian dan Pengangkutan Bulk Elpiji (SPPBE) yang berlokasi di daerah Langsa - Aceh Timur. Proses Non Destructive Testing - Ultrasonic Test [11] menggunakan alat Dakota CMXDL yang telah terkalibrasi dengan rentang pengukuran antara $3 \mathrm{~mm} \mathrm{~s} / \mathrm{d}$ $75 \mathrm{~mm}$. 


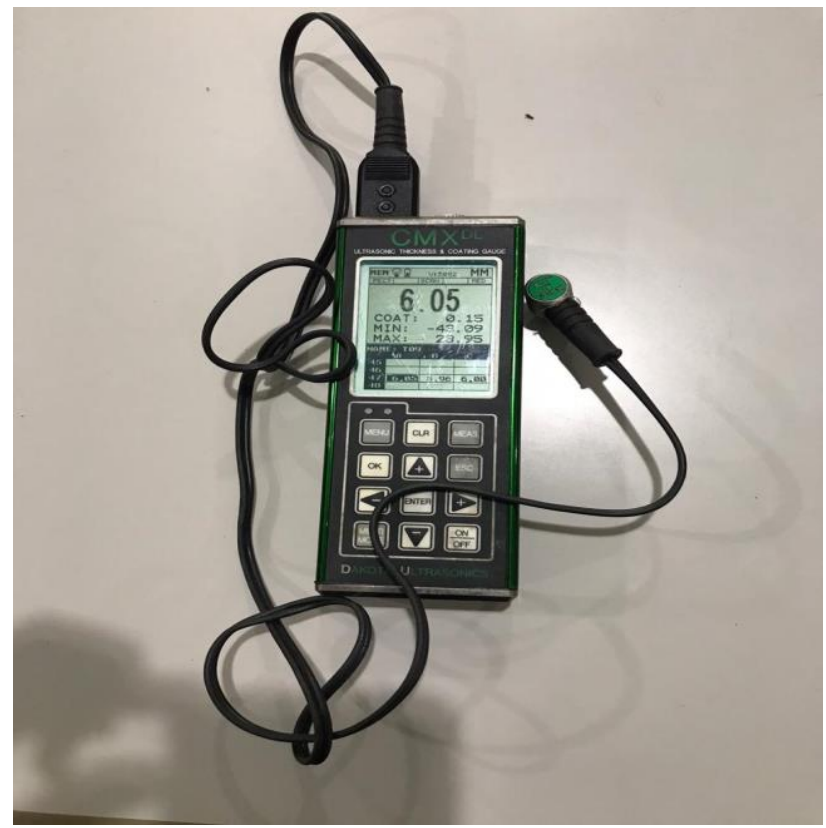

Gambar 3. Ultrasonic thickness - Dakota CMX DL

Selanjutnya proses visual inspeksi dan pengambilan data ketebalan dilakukan dengan disaksikan langsung oleh user selaku pemilik unit. Pengambilan data ketebalan Pressure vessel terdiri dari shell dan head, yang mana terdiri dari 5 shell dan 2 head, keterangan ini didapat dari hasil penelaahan gambar LPG Storage Tank. Titik pengambilan ketebalan dibagi menjadi 4 titik sudut yang terdiri dari $0^{\circ}, 90^{\circ}$, $180^{\circ}$ dan $270^{\circ}$ maka jika di total akan ada 28 titik pengambilan data ketebalan yang terdiri dari 8 titik ketebalan head dan 20 titik ketebalan shell. Dibawah ini merupakan skema pengambilan data ketebalan dari LPG Storage Tank $50 T$.

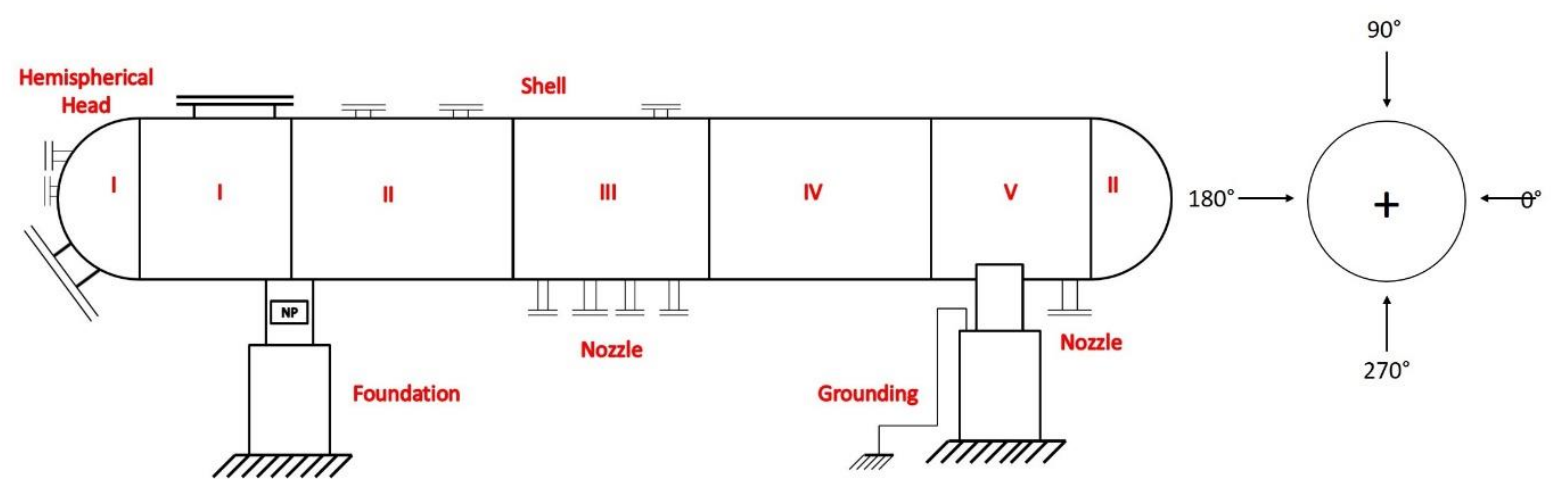

Gambar 4. Titik pengambilan ketebalan.

Dari nilai pengujian ketebalan head dan shell dengan menggunakan metode Ultrasonic Test akan diambil data ketebalan terkecil yang nanti nya akan dipakai untuk proses kalkulasi.

\section{HASIL DAN PEMBAHASAN}

Penelaahan dokumen dilakukan di awal penelitian untuk mendapatkan data teknis desain dan datadata pendukung lainnya. Setelah dilakukan telah maka didapat data teknis yang dijelaskan pada tabel 1 . 
Tabel 1. Data teknis LPG Storage Tank

\begin{tabular}{lc}
\hline \multicolumn{2}{c}{ Data teknis LPG Storage Tank 50 T } \\
\hline Design Pressure $\left(\mathrm{kg} / \mathrm{cm}^{2}\right)$ & 17.60 \\
MAWP $\left(\mathrm{kg} / \mathrm{cm}^{2}\right)$ & 17.60 \\
Design Temperature $\left({ }^{\circ} \mathrm{C}\right)$ & 55.00 \\
Hydrostatic Test $\left(\mathrm{kg} / \mathrm{cm}^{2}\right)$ & 23.40 \\
Capacity $($ Ton $)$ & 50.00 \\
Year Built & 2010 \\
Shell Material & SA $516 \mathrm{Gr} .70$ \\
Allowable stress shell $(P s i)$ & 1406.14 \\
Head Material & SA $516 \mathrm{Gr} .70$ \\
Allowable stress head $($ Psi) & 1406.14 \\
Inside Diameter $(\mathrm{mm})$ & 3300.00 \\
Overall Length $(\mathrm{mm})$ & 11250.00 \\
Joint Efficiency & 1.00 \\
Length of Radius $(\mathrm{mm})$ & 1636.00 \\
Nominal thickness of shell $(\mathrm{mm})$ & 22.00 \\
Previous thickness of shell $(\mathrm{mm})$ & 21.73 \\
Nominal thickness of head $(\mathrm{mm})$ & 14.00 \\
Previous thickness of head $(\mathrm{mm})$ & 13.69 \\
Year of Last inspection & 2017 \\
\hline
\end{tabular}

Setelah mendapatkan data teknis yang didapatkan melalui proses review dokumen, tahapan selanjutnya adalah inspeksi lapangan yang bertujuan untuk mendapatkan kondisi existing LPG Storage Tank serta nilai aktual ketebalan shell dan head. Kondisi existing pada LPG Storage Tank tergambarkan dalam beberapa dokumentasi yang diambil pada saat visual inspeksi dilakukan, terdapat beberapa spot uniform corrosion pada permukaan head dan shell.

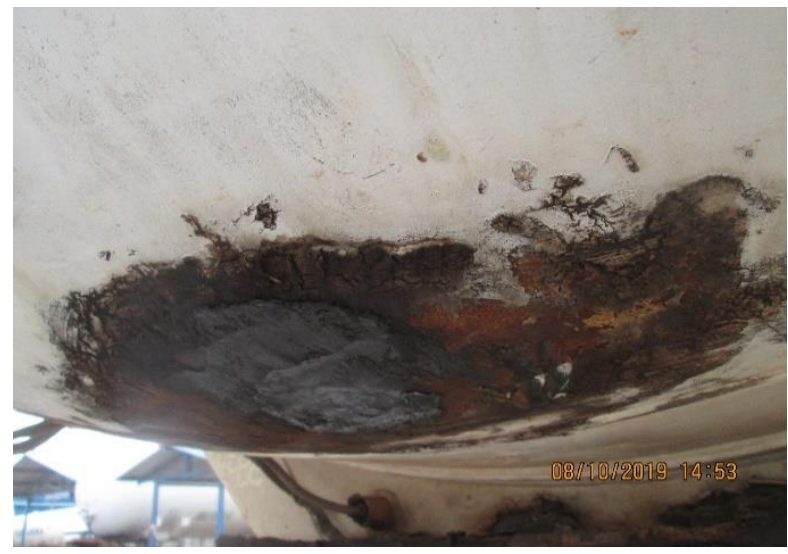

Gambar 5. Uniform corrosion pada head

Gambar 5 memberikan gambaran mengenai korosi yang terjadi pada bagian bawah head $L P G$ Storage tank. Korosi juga terjadi pada beberapa bagian head lainnya. 
Remaining Life Assessment dan Kasus Laju Korosi Pada LPG Storage Tank Kapasitas 50 Ton

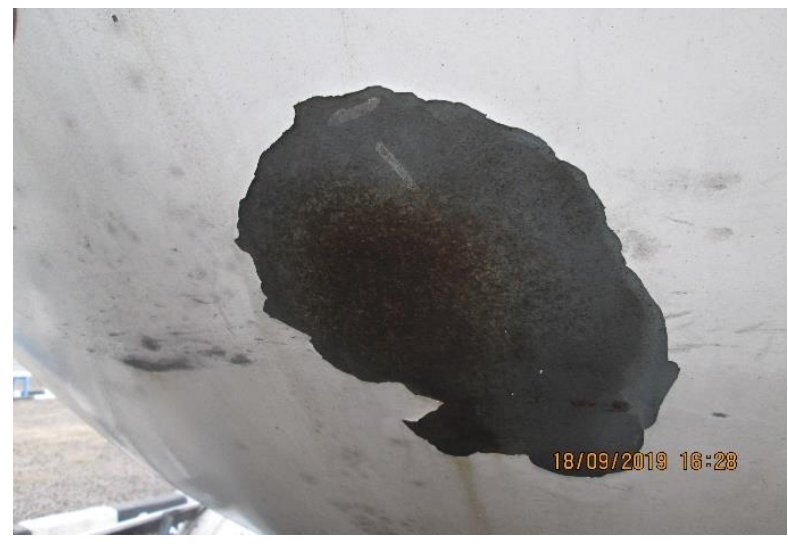

Gambar 6. Uniform corrosion pada bagian atas (2)

Kondisi korosi juga menyerang pada bagian lain, khususnya pada bagian bolt and nuts. Seperti yang terlihat pada gambar 7 .

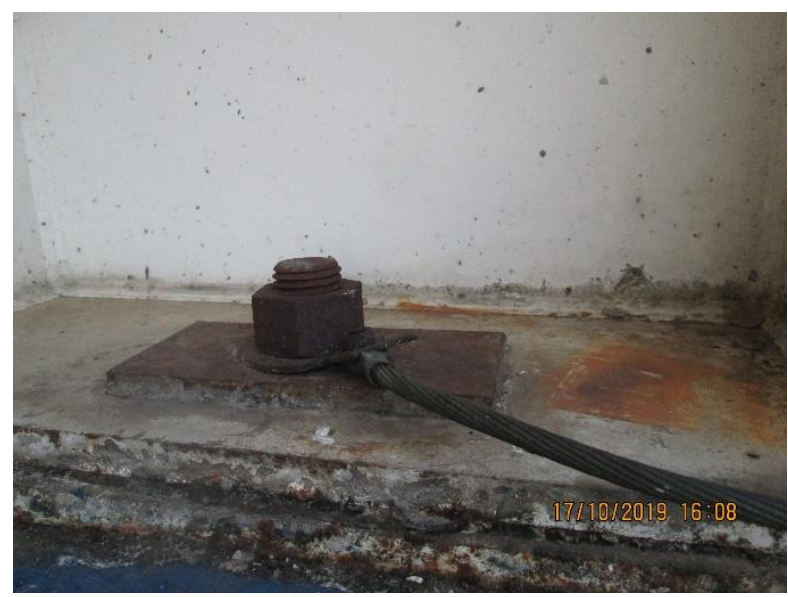

Gambar 7. Korosi pada bagian bolt and nut

Selain serangan korosi, terdapat banyak sekali kerusakan pada bagian painting permukaan $L P G$ Storage Tank hal tersebut bisa dilihat dari gambar 8.

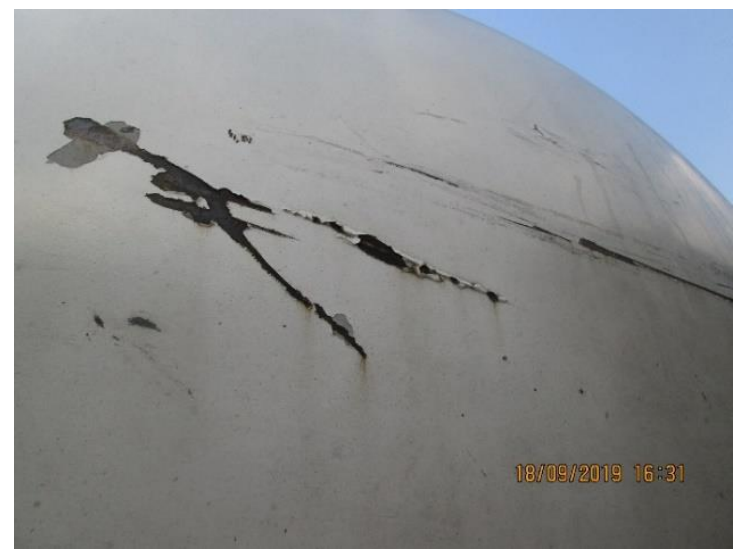

Gambar 8. Scratch pada permukaan. 
Proses visual inspeksi memberikan informasi mengenai kondisi terkini dari LPG Storage Tank sehingga dapat segera dilakukan tindakan corrective dan preventif [12]. Walaupun demikian proses inspeksi visual masih bersifat eksternal dan harus juga dilakukan peninjauan pada bagian internal $L P G$ Storage Tank pada saat Stasiun Pengangkutan dan Penimbunan Bulk Elpiji (SPPBE) dalam kondisi shut down. Selain itu bagian-bagian lain dan instrumentasi seperti ladder, platform, PSV, Foundation, Name Plate, Nozzle, Piping system, Pressure gauge, Temperature gauge, Sprinkler system dan Tank volume indicator pada $L P G$ Storage Tank masih dalam kondisi baik dan layak beroperasi.

Tahapan selanjutnya adalah melakukan uji ketebalan pada LPG Storage Tank menggunakan metode Ultrasonic Test (UT) sesuai dengan keterangan serta tahapan dalam bab metodologi. Setelah dilakukan pengukuran ketebalan pada permukaan LPG Storage Tank maka didapat hasil pengukuran dalam tabel 2.

Tabel 2. Hasil pengukuran ketebalan

\begin{tabular}{cccccc}
\hline \multicolumn{5}{c}{ Aktual Ketebalan LPG Storage Tank 50 T } \\
\hline $\begin{array}{c}\text { Titik } \\
\text { Lokasi }\end{array}$ & $0^{\circ}$ & $90^{\circ}$ & $180^{\circ}$ & $270^{\circ}$ & Ketebalan sebelumnya \\
\hline Head 1 & 14,00 & 14,10 & 13,90 & 13,60 & \\
Head 2 & 14,00 & 13,60 & 13,60 & 13,70 & \\
Shell 1 & 21,60 & 21,70 & 22,00 & 21,70 & Shell : 21,73 Head: \\
Shell 2 & 21,60 & 21,90 & 21,60 & 22,00 & 13,69 \\
Shell 3 & 21,60 & 22,00 & 21,60 & 22,00 & \\
Shell 4 & 21,70 & 22,10 & 21,70 & 21,90 & \\
Shell 5 & 21,80 & 22,10 & 21,80 & 21,90 & \\
\hline
\end{tabular}

Berdasarkan tabel pengukuran ketebalan diatas, didapat bahwa untuk ketebalan terkecil untuk shell adalah pada shell 1 , shell 2 dan shell 3 dengan titik lokasi $0^{\circ}$ dan $180^{\circ}$ dari name plate dengan nilai hasil pengukuran sebesar 21,60 mm sementara untuk ketebalan pada head terdapat pada head 1 dan head 2 dengan titik lokasi $90^{\circ}, 180^{\circ}$ dan $270^{\circ}$ dari name plate dengan hasil pengukuran sebesar $13,60 \mathrm{~mm}$. Dengan data tersebut kita bisa langsung melakukan proses kalkulasi terhadap LPG Storage Tank.

Tahap pertama yang dilakukan adalah peninjauan kelayakan shell dan head berdasarkan nilai ketebalan aktual yang didapat untuk mencari nilai ketebalan minimum yang diperbolehkan menggunakan formula (1) pada bab studi literatur. Ketebalan minimum adalah ketebalan yang disyaratkan (Treq+CA) sehingga

treq $=\frac{17,6(1650+0,00)}{[(1406,14 \times 1)-(0,6(17,60))]}=20,81 \mathrm{~mm}$ 
Berdasarkan kalkulasi diatas maka dapat ditarik kesimpulan jika LPG Storage Tank pada bagian shell masih dapat dipergunakan karena nilai ketebalan minimum lebih kecil dibandingkan dengan ketebalan aktual $(20,81 \mathrm{~mm}<21,6 \mathrm{~mm})$.

Sementara itu untuk nilai kalkulasi pada head LPG Storage Tank

treq $=\frac{17,6 \times 1636}{[(2 \times 1406,14 \times 1)-(0,2 \times 17,6)]}=10,25 \mathrm{~mm}$

Berdasarkan ketebalan aktual sebesar 13,6 mm maka dapat ditarik kesimpulan bahwa bagian head dari LPG Storage Tank masih layak dan aman dipergunakan karena nilai ketebalan aktual lebih besar dibandingkan dengan ketebalan minimum hasil kalkulasi $(10,25 \mathrm{~mm}<13,6 \mathrm{~mm})$.

Selanjutnya memperhitungkan laju korosi pada head dan shell dengan kondisi short term dan long term sesuai dengan formula yang terdapat pada bab studi literatur. Data ketebalan sebelumnya dilakukan pada tahun 2017 sehingga rentang waktu antara previous thickness dan actual thickness adalah 3 tahun baik itu pada shell ataupun pada head. Perhitungan laju korosi saat kondisi short term.

- Short term shell

$C R: \frac{21,73-21,60}{2020-2017}=0,043 \mathrm{~mm} / \mathrm{yr}$

- Short term head

$C R: \frac{13,69-13,60}{2020-2017}=0,03 \mathrm{~mm} / \mathrm{yr}$

Sehingga didapat untuk short term corrosion rate shell dan head adalah $0,043 \mathrm{~mm} / \mathrm{thn}$ dan 0,03 $\mathrm{mm} / \mathrm{thn}$. Dan untuk long term corrosion rate adalah kondisi antara nominal thickness pada saat awal fabrikasi dengan actual thickness sehingga didapat jarak antara keduanya adalah 10 tahun. Perhitungan laju korosi saat kondisi long term.

\section{- Long term shell}

$C R: \frac{22,0-21,6}{2020-2010}=0,040 \mathrm{~mm} / \mathrm{yr}$

- Long term head

$C R: \frac{14-13,6}{2020-2010}=0,040 \mathrm{~mm} / \mathrm{yr}$

Sehingga didapat nilai long term corrosion rate pada head dan shell LPG Storage Tank adalah 0,04 $\mathrm{mm} / \mathrm{thn}$. Nilai dari laju korosi dapat dipakai untuk memperhitungkan nilai tekanan maksimum yang diijinkan (MAWP).

Tahapan selanjutnya merupakan mengkalkulasi nilai maximum allowable working pressure (MAWP) mempergunakan data kalkulasi dari ketebalan aktual yang didapat. Dengan menggunakan formula pada bab studi literatur maka nilai MAWP untuk head dan shell. 
MAWP Shell

$M A W P=\frac{1406,14 \times 1(21,60-2(0,043) \times 3)}{(1650+0)+0,6(21,60-2(0,043) \times 3)}=17,97 \mathrm{~kg} / \mathrm{cm}^{2}$

MAWP Head (Hemispherical)

$M A W P=\frac{1406,14(1)(13,69-2(0,043) x(3))}{1636+0,2(13,69-2(0,043) x(3))}=22,75 \mathrm{~kg} / \mathrm{cm}^{2}$

Berdasarkan kalkulasi diatas maka didapat bahwa nilai MAWP untuk shell dan head dari LPG Storage Tank adalah $17,97 \mathrm{~kg} / \mathrm{cm}^{2}$ dan $22,75 \mathrm{~kg} / \mathrm{cm}^{2}$. Sehingga batas diperbolehkan nya LPG Storage tank beroperasi adalah pressure dalam LPG Storage Tank tidak boleh lebih dari minimum MAWP yaitu sebesar $17,97 \mathrm{~kg} / \mathrm{cm} 2$. Selanjutnya adalah menghitung sisa umur pakai atau remaining life dari $L P G$ Storage Tank

\section{Remaining life shell}

Remaining Life $=\frac{21,60-20,81}{0,043}=18$ tahun

\section{Remaining life head}

Remaining Life $=\frac{13,60-10,25}{0,043}=77$ tahun

Berdasarkan kalkulasi maka dapat ditarik kesimpulan bahwa sisa umur pakai dari LPG Storage tank adalah minimum remaining life of shell and head yaitu 18 tahun.

\section{SIMPULAN}

LPG storage tank masih dalam kategori layak pakai walaupun harus dilakukan repainting pada beberapa permukaan bejana tekan yang terkelupas dan korosi. Nilai ketebalan setelah dilakukan peninjauan langsung ke lapangan adalah 21,60 mm untuk shell dan 13,60 mm untuk head. Nilai ketebalan yang disyaratkan untuk shell dan head adalah 20,81 mm dan 10,25 mm, sehingga LPG Storage Tank masih layak beroperasi. Nilai untuk laju korosi pada shell dan head berdasarkan short term adalah $0,043 \mathrm{~mm} / \mathrm{thn}$ dan $0,03 \mathrm{~mm} / \mathrm{thn}$ lalu untuk long term adalah $0,040 \mathrm{~mm} / \mathrm{thn}$. Nilai untuk MAWP shell dan head adalah $17,97 \mathrm{~kg} / \mathrm{cm}^{2}$ dan $22,75 \mathrm{~kg} / \mathrm{cm}^{2}$. Sedangkan untuk sisa umur pakai dari LPG storage tank adalah 18 tahun untuk shell dan 77 tahun untuk head. Untuk penelitian selanjutnya disarankan agar melakukan pengambilan data thickness lebih banyak dan dalam kondisi shutdown sehingga bagian internal dari $L P G$ storage tank bisa dijangkau.

\section{DAFTAR PUSTAKA}

[1] S. Renaningsih, "IDENTIFIKASI M E T O D A U J I B E J A N A T E K A N R E A K T O R 
AIR BERTEKANAN UNTUK M E N U N J A N G KESELAMATAN REAKTOR,” pp. 32$38,2000$.

[2] D. Berbagai and K. H. S. O. Dan, "Spesimen yang digunakan pada penelitian ini adalah,” vol. 14, no. 1, pp. 10-13, 2010.

[3] D. Vavrik, J. Jakubek, I. Kumpova, and M. Pichotka, "Dual energy CT inspection of a carbon fibre reinforced plastic composite combined with metal components," Case Stud. Nondestruct. Test. Eval., vol. 6, pp. 47-55, 2016.

[4] API, "Pressure Vessel Inspection Code: In-Service Inspection, Rating, Repair, and Alteration," Api 510, vol. 552, no. 1, p. iii, 2006.

[5] U. Test, "ANALISA SISA UMUR PEMAKAIAN (REMAINING LIFE ASSESMENT) AIR RECEIVER COMPRESSOR TANK MENGGUNAKAN METODE ULTRASONIC TEST Fuad Khoirul 1, Muh Amin 2 , Muhammad Subri 3 ABSTRAK,” vol. 17, no. 1, pp. 10-20.

[6] N. V. Raghavaiah, “ $\square$ Overview of Pressure Vessel Design using ASME Boiler and Pressure Vessel Code Section VIII Division-1 and Division-2,” no. March, pp. 1-3, 2020.

[7] S. ASME, "2017 Boiler and Pressure Vessel Code, An International Code BPVC17," ASME Boil. Press. Vessel Code, p. 25, 2017.

[8] P. Se, "Pr c se 0.6 p," pp. 1-14, 2004.

[9] R. A. Pitalokha, M. R. Hamdani, and A. Taufik, "Kajian Risk Based Inspection untuk Separator dan Heat Exchanger pada Liquefied Natural Gas Plant,” pp. 64-73, 2016.

[10] R. Oktoriansyah, B. Hartono, and E. Sutoyo, "Analisa Laju Korosi Akibat Pengelasan Duplex UNS32205 Dengan 2 Metode Pengelasan yang Berbeda Pada Media FeCl3," AME (Aplikasi Mek. ..., pp. 77-82, 2017.

[11] Z. Li and Z. Meng, "A review of the radio frequency non-destructive testing for carbon-fibre composites," Meas. Sci. Rev., vol. 16, no. 2, pp. 68-76, 2016.

[12] G. Lackner and P. Tscheliesnig, "Requalification of LPG tanks in Europe: Verifying the structural integrity by monitoring the pressure test with acoustic emission," Insight NonDestructive Test. Cond. Monit., vol. 58, no. 8, pp. 443-447, 2016. 